DOI 10.37882/2223-2982.2020.12-3.19

\title{
ГЕНДЕРНЫЙ ПОДХОД К ФОРМИРОВАНИЮ ФИЗИЧЕСКОЙ КУЛЬТУРЫ У ДЕТЕЙ СТАРШЕГО ДОШКОЛЬНОГО ВОЗРАСТА
}

\section{GENDER APPROACH TO THE FORMATION OF PHYSICAL CULTURE IN OLDER PRESCHOOL CHILDREN}

M. Popkov

Summary: This article analyzes the preconditions for the use of a gender approach to the problem of the formation of physical culture in older preschool children studying at preschool educational institutions. In addition, we offer the following components of the personal physical culture of children in terms of a gender approach to the organization of physical education classes: cognitive-meaningful, motivational-value, organizational-activity.

Keywords: gender, gender approach, physical culture, physical education, senior preschool age.

\author{
Попков Максим Вячеславович \\ аспирант, Рязанский государственный \\ университет имени С.А. Есенина, \\ popkov-2015@list.ru
}

Аннотация: В данной статье анализируются предпосылки использования гендерного подхода к проблеме формирования физической культуры у детей старшего дошкольного возраста, обучающихся в ДОУ, предлагаются компоненты личностной физической культуры детей в условиях гендерного подхода к организации занятий физического воспитания: когнитивно-содержательный, мотивационно-ценностный, организационно-деятельностный.

Ключевые слова: гендер, гендерный подход, физическая культура, физическое воспитание, старший дошкольный возраст.

сохранение и укрепление здоровья детей, повышение уровня физической культуры, как основополагающий принцип эффективного развития всех сторон жизнедеятельности [4]. Анализируя компоненты личностной физической культуры дошкольника, мы определили следующие из них, относящиеся к категории базовых:

а) когнитивно-содержательный компонент, предполагающий присвоение детьми совокупности основополагающих теоретических знаний о ценностях физической культуры, отражающих как личностную, так и социальную сферу;

б) мотивационно-целевой компонент, определяющий образовательные потребности в процессе физического воспитания детей дошкольного возраста;

в) организационно-деятельностный компонент, характеризующий направление развития двигательного потенциала детей на занятиях физической культуры в ДОУ в условиях гендерного подхода к организации этих занятий.

Однако значительная часть ученых и педагоговпрактиков (Н.Л. Белопольская, М.Н. Терещенко, С.М. Ахметов) полагает, что существующее научно-методическое обеспечение процесса формирования физической культуры у детей старшего дошкольного возраста имеет множество недостатков, что приводит к снижению результативности данного процесса. Так одним из главных недостатков является отсутствие методических рекомендаций по реализации гендерного подхода к формированию физической культуры ребенка в услови- 
ях половых различий детей. Так мальчики на уроках физкультуры в ДОУ получают более простые инструкции, ориентированные на выполнение конкретных задач, и на них также распространяется более жесткая дисциплина, в то время как целью учителей физического воспитания было поощрение и мотивация девочек к более активному участию в занятиях спортом и физической культурой.

В рамках нашего исследования понятие «гендер» в отличие от «пола» определяет степень, в которой мальчики отличаются от девочек, затрагивая не только биологические, но и небиологические аспекты личности, такие как психологические, социальные и культурные различия [3]. По мнению многих ученых гендерная идентичность человека является не только биологическим фактором, определяющим его субъектность, но и формируется в результате длительного процесса социализации индивидуума. Результаты опытно-экспериментальной работы, проведенной нами по проблеме формирования физической культуры детей в условиях гендерного подхода, показали, что в старшем дошкольном возрасте мальчики «обгоняют» девочек по следующим показателям: мотивация к занятиям физической культурой, двигательная активность, физические возможности; проявление смелости, выносливости, агрессии. Девочки возраста от трех до шести лет проявили развитость, по сравнению с мальчиками, таких психических процессов, как внимание, мышление, воображение, речь. При этом, если причина такого показателя, как агрессия, у мальчиков связано с социально-одобряемой нормой поведения, то у девочек агрессия связана с тревожностью. Выравнивание психических показателей, по мнению М.М. Безруких, у мальчиков и девочек происходит примерно к 11-12 годам [1].

Анализ отечественной и зарубежной научной литературы по проблеме гендерного подхода к формированию физической культуры у дошкольников показал, что в целом у ученых существует единое мнение о наличии социальных гендерных различий у мальчиков и дево- чек старшего дошкольного возраста. Методологические споры ведутся многими учеными только о соотношении онтогенетического и социального в процессе гендерной идентификации детей.

Таким образом, мы делаем вывод о том, что процесс формирования физической культуры у детей старшего дошкольного возраста невозможно реализовать в ДОУ без опоры на гендерный подход, который предполагает ориентацию не на условного ребенка, а на мальчика и девочку. Принципиальными для обоснования использования гендерного подхода к формированию физической культуры у детей старшего дошкольного возраста стали работы М.М. Рубинштейна, который считал, что онтогенетика и социализация личности являются первопричиной, управляющей развитием человека [2]. Так М.М. Рубинштейн утверждал, что проблема физического воспитания детей на основе гендерного подхода есть проблема «философии культуры», которая должна опираться на равную ценность, а не тождественность мужского и женского начала.

Тем не менее, несмотря на актуальность гендерного подхода к формированию физической культуры мальчиков и девочек старшего дошкольного возраста, приходится констатировать, что существующие программы обучения в ДОУ направлены на «условного» бесполого ребенка, т.к. квалификация преподавателей физического воспитания в вопросах составления программ воспитания с учетом гендерных особенностей детей недостаточна.

В связи с этим считаем подчеркнуть следующее: 1) гендерные особенности детей необходимо рассматривать с позиции целостности личности ребенка; 2) несмотря на достаточно большое количество научных работ по данной проблеме, необходимо продолжать комплексные исследования проблемы гендерной идентичности, по результатам которых можно оптимизировать процесс физического воспитания в ДОУ с целью более эффективного развития детей в том числе и в вопросе их физической культуры.

ЛИТЕРАТУРА

1. Безруких, М.М. Возрастная физиология: (Физиология развития ребёнка): учеб. пособие для студ. высш. пед. учеб. заведений / М.М. Безруких, В.Д. Сонькин, Д.А. Фарбер. - М.: Издательский центр «Академия», 2003. - 416 с.

2. Рубинштейн, М.М. Половое воспитание с точки зрения интересов культуры / М.М. Рубинштейн. - М.; Л.: Моск. акц. изд. 0-во, 1926. - 126 с.

3. Солодков, А.С. Физиология человека. Общая. Спортивная. Возрастная: учебник. - Изд. 2-е, испр. и доп. / А.С. Солодков, Е.Б. Сологуб. - М.: Олимпия Пресс, 2005. -528 C.

4. Фомина, Н.А. Физическое воспитание детей дошкольного возраста на основе интегрированного подхода / Н.А. Фомина, С.В. Карпушина. - Волгоград: ФГБОУ ВПО «ВГАФК», 2012. - С. 51-56.

(с) Попков Максим Вячеславович (popkov-2015@list.ru).

Журнал «Современная наука: актуальные проблемы теории и практики» 